OPEN ACCESS

Edited by:

Colin Baker,

University of Gloucestershire,

United Kingdom

Reviewed by:

Todd Allen Telemeco,

University of North Carolina at

Pembroke, United States

Mohammad Ali Morowatisharifabad,

Shahid Sadoughi University of Medical

Sciences and Health Services, Iran

Fazlollah Ghofranipour,

Tarbiat Modares University, Iran

*Correspondence:

Mohammad Hossein Kaveh mhkaveh255@gmail.com

TORCID:

Mohadeseh Motamed-Jahromi 0000-0001-6025-4879

Mohammad Hossein Kaveh

0000-0002-9141-3243

Specialty section: This article was submitted to

Public Health Education and

Promotion,

a section of the journal

Frontiers in Public Health

Received: 29 November 2019 Accepted: 02 November 2020

Published: 15 February 2021

Citation:

Motamed-Jahromi M and Kaveh MH

(2021) Effective Interventions on Improving Elderly's Independence in Activity of Daily Living: A Systematic

Review and Logic Model.

Front. Public Health 8:516151.

doi: 10.3389/fpubh.2020.516151

\section{Effective Interventions on Improving Elderly's Independence in Activity of Daily Living: A Systematic Review and Logic Model}

\author{
Mohadeseh Motamed-Jahromi ${ }^{1 \dagger}$ and Mohammad Hossein Kaveh ${ }^{2 *+}$ \\ ${ }^{1}$ Department of Health Promotion, School of Health, Shiraz University of Medical Sciences, Shiraz, Iran, ${ }^{2}$ Research Center \\ for Health Sciences, Institute of Health, Department of Health Promotion, School of Health, Shiraz University of Medical \\ Sciences, Shiraz, Iran
}

This systematic review aimed to investigate the types and characteristics of effective interventions when improving the independence of the elderly during activities of daily living. After developing a search strategy, the various databases, including PubMed, Scopus, Cochrane Library, Science Direct, Proquest, and Embase, were searched up to October 16, 2019. The Review Manager 5.1 software was used to determine the risk of bias. The randomized clinical trials were reviewed to find if their interventions' main goal was to improve the elderly's independence in activities of daily living. Data were extracted independently by two authors. Eight randomized controlled trials were included in the final analysis. Three types of interventions were identified and categorized as cognitive training, physical exercises, and multicomponent interventions. All reviewed studies provided evidence of the effectiveness of interventions in improving older people's ability to perform the activities of daily living. However, the lack of uniform measurement indicators to identify and compare the most effective interventions forced us to develop a conceptual framework for designing future interventional research. This conceptual framework included designing tailored interventions, creating an age-friendly environment as well as financial, psychological, and social support. The proposed conceptual framework can also help develop future systematic reviews focusing on a particular intervention type.

Keywords: independent living, systematic review, elderly, aged, activity of daily living

\section{INTRODUCTION}

Independence among the elderly when performing individual and social tasks is a very challenging issue in all societies. Independence is considered self-determination, emancipation from coercion, and freedom of thought, selection, and performance $(1,2)$. Independence among the elderly is defined as the degree of individual autonomy in meeting their daily needs (eating, dressing, showering, etc.) and their right to choose (3). During the aging process, implicit physical, physiological, psychological, and social changes generate disability in activities of daily living and reduce independence $(4,5)$. Activities of daily living include Basic Activities of Daily Living (BADLs) and Instrumental Activities of Daily Living (IADLs) (6). BADLs include self-care skills such as bathing, dressing, eating, and IADLs, including more complex activities such as using the 


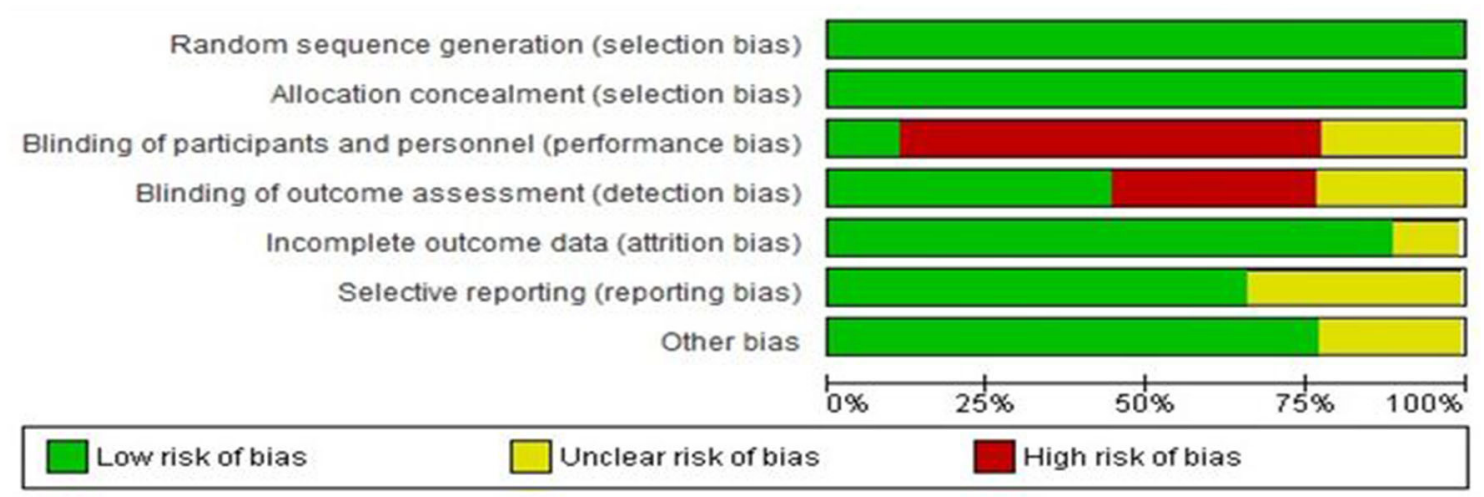

FIGURE 1 | Risk of bias graph: review authors' judgments about each risk of bias item presented as percentages across all included studies.

public transport system, financial management, and buying (7). Decreased independence in the elderly has unpleasant consequences and can cause dependence on others in activities of daily living (ADLs), reduce quality of life, and damage health (8). So it is crucial to maintain the elderly's ability and independence in ADLs (9).

A review of health promotion initiatives showed that various interventions with varying degrees of effectiveness were examined to enhance the elderly's activities of daily living in different studies. Some studies have focused on physical activity, especially mobility exercise and functional training, to improve muscle strength, balance, and ADL (10, 11). Some other studies have measured the effect of cognitive interventions on improving the elderly's performance in $\mathrm{ADL}(12,13)$. A cross-sectional study has also documented that the living environment changes can facilitate the activity and presence of the elderly in the community and thus help increase their independence (14). The question is what kind of interventions can help promote the elderly's independence in activities of daily living and the characteristics of the successful interventions in ADL independence?

In the last decade, several systematic reviews have focused on the elderly's physical functioning and quality of life. Still, their primary purpose was not to investigate effective interventions in terms of the elderly's ADL independence and measure it $(10,11$, 15-17). The systematic review of Beswick et al. (18) was the only study to examine the impact of community-based interventions on maintaining the elderly's physical activity and independence. This study has reported a combination of interventions, including education and counseling, fall prevention, communitybased care, and interventions aiming to change the elderly's physical and social environment. Still, it did not include cognitive and physical interventions (18). Although various interventions have been reported in the literature to improve the elderly's ability to perform ADLs, it seems most healthcare providers have focused on physical interventions in practice. Therefore, a systematic review of articles can provide them with a list of effective interventions. Consequently, this review was conducted to identify the types and the characteristics of interventions effective in promoting the elderly's independence in practicing their activities of daily living.

\section{METHODS}

This systematic review, which was designed in 2019, is based on the Preferred Reporting Items for Systematic Reviews and Meta-Analysis checklist (PRISMA) (19).

We adopted a four-step search strategy to identify relevant articles. First, the PICo strategy based on the Joanna Briggs Institute (20) was used for a research question defined as what kind of interventions were used to increase the elderly's independence in daily living activities in randomized controlled trials? After that, the PICo framework contributed to the definition of the inclusion criteria-Population: elderly; Intervention: cognitive, physical, and environmental interventions; Context: dwelling in the community; and Outcome: independence in ADL. Second, the search was conducted without a time limit up to October 16, 2019 in PubMed, Cochrane trial, Scopus, Science Direct, Proquest, and Embase databases. See Supplementary Material for the search strategy. Third, Google and Google scholar were searched for gray literature. Fourth, search results of all databases collected in the EndNote X7 software and duplicate articles were removed.

\section{Study Criteria}

Studies were individually screened in two steps: screening titles and abstracts and screening full-text articles by two investigators using eligibility criteria. Articles with these characteristics were selected to review (a) randomized controlled trials; (b) study participants, including the elderly without Alzheimer, cognitive problems, and impaired mental function; (c) using one or more interventions to improve the elderly's ADL independence; (d) directly or indirectly measuring older people's ability and independence in performing individual or social ADL, and (e) English language studies. The exclusion criteria were nonoriginal articles, including letters to the editor, case reports, review and meta-analysis studies, and articles presented at 


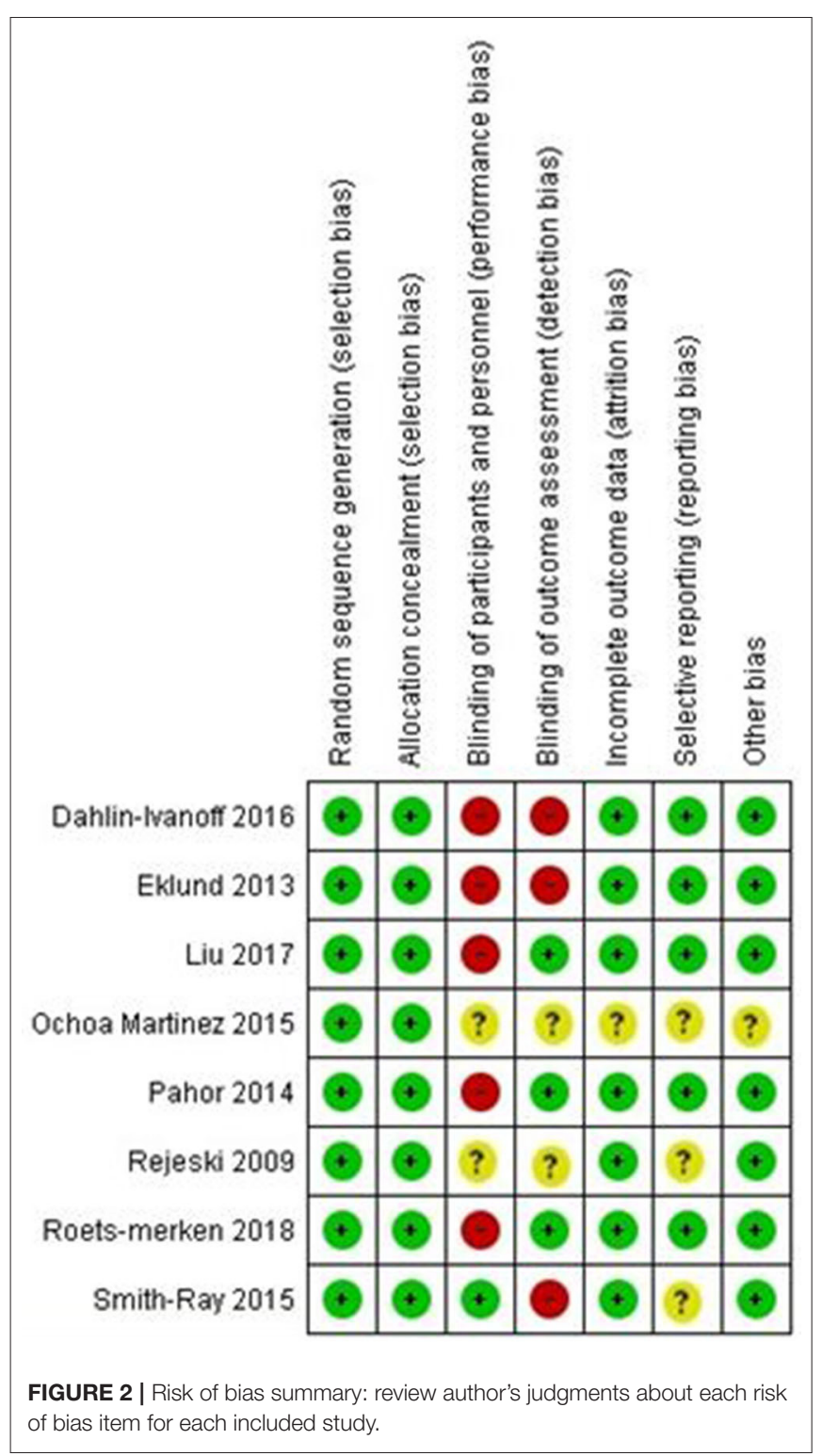

conferences. It should be noted that articles without full text were excluded.

\section{Risk of Bias in Included Studies}

Review Manager 5.1 (RevMan) software was used to determine the risk of bias. Details of the risk-of-bias items are presented separately in each article in Figures 1, 2.

\section{Data Synthesis}

We did not perform a meta-analysis due to heterogeneity in quantitative indices and outcome measurement tools. Instead, we chose a narrative approach to synthesis according to the steps outlined in the Center for Reviews and Dissemination Guidance: developing a theory of how the intervention works, why and for whom, developing a preliminary synthesis of results of included studies, exploring relationships in the data, considering the robustness of the synthesis (21).

\section{RESULTS}

\section{Description of Studies}

A total of 343 articles were found after searching the database. Then, 212 articles remained after removing the duplicate articles. After reviewing the articles' titles and abstracts, 33 articles entered the next stage. At this stage, the articles' full texts were reviewed, and eight RCT studies entered the final analysis. Several articles were excluded in the screening stages of studies for various reasons, such as non-relevant topics, non-interventional subjects, and non-original articles. The flowchart of the studies entered is shown in Figure 3.

\section{Study Characteristic}

Eight eligible randomized controlled trials were conducted in four different countries, including the USA (four studies), Sweden (two studies), Netherland (one study), and Mexico (one study) (22-29). The sample size varied from 26 (25) to 1,635 participants (26), with an average of 354 participants. The interventions' duration varied from 10 weeks $(24,29)$ to 12 months $(26,27)$. The follow-up time range varied from a very brief follow-up (29) to 36 months (27). The characteristics of the studies are summarized in Table $\mathbf{1 .}$

Based on the overall key risk of bias items, seven $(87 \%)$ of eight articles were rated as low risk of bias (studies with three or more items were considered low risk). Seven (87\%) studies were identified as high or unclear risk of performance, indicating that participants were not blind in five studies, and in two studies, their blindness was unclear. In three studies, the assessor was not blind, there was an unclear risk of detection bias in two articles, and attrition rates were clearly reported in seven articles (Figure 2).

Different interventional programs have been used in selected articles to promote the elderly's independence that can be divided into three categories of cognitive, physical, and multicomponent interventions. Two of the eight articles utilized cognitive interventions to improve ADLs, including "the self-management program" (SMP) (28) and "cognitive training programs and the computer software program, Insight” (29). Two articles focused on the elderly's physical training intervention, which included the three-step workout for life (24) and the water exercise training program (25). Four articles also used three multicomponent interventions, including the Elderly Persons in the Risk Zone (EPRZ) (22), "Lifestyle and Independence Interventions for the Elderly" (LIFE) $(26,27)$, and a Continuum of Care for Frail Older People (23).

Between cognitive interventions, SMP focused on improving the elderly's IADLs with five skills: problem-solving, decisionmaking, resource utilization, formulation of participation, and actions (28). The insight program was another cognitive intervention that emphasized promoting BADLs by improving executive function, including working memory, processing speed, and inhibition, using three different games: Road Tour, Jewel Diver, and Sweep Seeker (29).

As a physical training intervention, a three-step workout for life program focused on slowing down disability in the elderly and improving performance in ADLs. In this exercise, 




functional movements, selective daily activities, and resistance exercises were used three times a week, $60 \mathrm{~min}$ each time, for 10 weeks (24). The other physical intervention was water exercise training, which revealed significant improvement in the elderly's functional independence. Five water exercises were performed in this intervention, including walking 10 meters, standing up from a chair and walking straightaway, dressing and undressing, standing up from a sitting position, and standing up from a lying position (25).

One of the multicomponent interventions was the LIFE protocol consisting of cognitive and physical interventions (26, 27). The LIFE protocol had several components: social cognitive theory (self-efficacy and outcome expectations) (36), aerobics, endurance exercises, and flexible training activities. This program was finally able to improve BADLs (18). The EPRZ program focused on the elderly's independence in ADL and encouraged the elderly to decide independently and gain control over their lives and learn how to turn their home into an age-friendly environment (22). "Continuum of care for frail older people" was a program that concentrated on interprofessional shared decision-making for continuous care (23). The independence of the elderly in this program was improved in five BADLs (bathing, dressing, going to the toilet, transferring, and feeding) and four IADLs (cleaning, buying, transporting, and cooking) (33). 
TABLE 1 | Summary of the included RCT studies.

\begin{tabular}{|c|c|c|c|c|c|}
\hline Results & ADL or independence scales & $\begin{array}{l}\text { Duratio } \\
\text { month }\end{array}$ & $\begin{array}{l}\text { Interventions to } \\
\text { maintain independence }\end{array}$ & Country/Year & Authors \\
\hline $\begin{array}{l}\text { SMP was more effective in } \\
\text { IADL }\end{array}$ & $\begin{array}{l}\text {-The Patient Autonomy Questionnaire } \\
\text { (PAQ) (30) } \\
\text { - Activity Card Sort (ACS) (31):-4 } \\
\text { domains: } \\
\text { Instrumental activities of daily living } \\
\text { (IADL) } \\
\text { Social-cultural activities } \\
\text { High-physical-demand leisure activities } \\
\text { Low-physical-demand leisure activities. }\end{array}$ & 5 & $\begin{array}{l}\text { - Self-management program (SMP) (32): } \\
\text { - Problem-solving approach-5 steps: } \\
\text { Problem identification } \\
\text { Collecting alternatives } \\
\text { Choice and planning } \\
\text { Execution } \\
\text { Reflection }\end{array}$ & Netherlands 2018 & $\begin{array}{l}\text { Roets-Merken et } \\
\text { al. (28) }\end{array}$ \\
\hline $\begin{array}{l}\text { 3-Step Workout for Life } \\
\text { improves the performance } \\
\text { of ADLs for older adults who- } \\
\text { are at risk of losing } \\
\text { independence at home. }\end{array}$ & $\begin{array}{l}\text { - Assessment of Motor \& Process } \\
\text { Skills (AMPS): } \\
\text { - A standardized observational evaluation } \\
\text { - Evaluation of } 16 \text { motor skills and } 20 \\
\text { process skills of familiar ADL }\end{array}$ & 2.5 & $\begin{array}{l}\text { - The 3-Step Workout for Life } \\
\text { program (24): } \\
\text { - Task-oriented approach-3 components: } \\
\text { Muscle strength training } \\
\text { Functional training } \\
\text { ADL training }\end{array}$ & USA 2017 & Liu et al. (24) \\
\hline $\begin{array}{l}\text { Maintaining balance and } \\
\text { gait through improving } \\
\text { working memory and speed } \\
\text { processing. }\end{array}$ & $\begin{array}{l}\text { - Measurement of ADL through a } \\
\text { demographic questionnaire } \\
\text { - Berg Balance Scale } \\
\text { - Functional balance test }\end{array}$ & 2.5 & $\begin{array}{l}\text { - A computer-based cognitive training } \\
\text { program "Insight" :-3 simple computer } \\
\text { games target executive function domains } \\
\text { - A self-driven program that adapts to the } \\
\text { individual's performance by increasing or } \\
\text { decreasing task difficulty }\end{array}$ & USA 2015 & $\begin{array}{l}\text { Smith-Ray et al. } \\
\text { (29) }\end{array}$ \\
\hline $\begin{array}{l}\text { Positive improvements in } \\
\text { functional autonomy }\end{array}$ & $\begin{array}{l}\text { - } 5 \text { tests to determine the functional } \\
\text { autonomy according to GDLAM } \\
\text { protocol } \\
10 \mathrm{~m} \text { walk (10 mW) } \\
\text { Getting up from a seated position (GSP) } \\
\text { Getting up from the prone position } \\
\text { (GPP) } \\
\text { Getting up from a chair and movement } \\
\text { around the house (GCMH) } \\
\text { Putting on and taking off a shirt (PTS) }\end{array}$ & 3 & $\begin{array}{l}\text { - Water exercise training program: } \\
\text { - Five times a week, with } 50 \text { min per session } \\
\text { for } 3 \text { months } \\
\text { - Providing functional autonomy (34) }\end{array}$ & Mexico 2015 & $\begin{array}{l}\text { Ochoa Martínez et } \\
\text { al. (25) }\end{array}$ \\
\hline $\begin{array}{l}\text { Promoting } A D L \\
\text { independence up to } 1 \text { year } \\
\text { and postponing } A D L \\
\text { dependence up to } 6 \text { months }\end{array}$ & $\begin{array}{l}\text { - ADL staircase } \\
\text { - Evaluation of ADL } \\
\text { - A scoring range of independence } \\
\text { to dependency }\end{array}$ & 6 & $\begin{array}{l}\text { - Continuum of Care for Frail } \\
\text { Older People: } \\
\text { - An integrated care and rehabilitation by a } \\
\text { multi-professional team from hospital } \\
\text { to homes }\end{array}$ & Sweden 2013 & Eklund et al. (23) \\
\hline $\begin{array}{l}\text { Better SPPB and walking } \\
\text { speed }\end{array}$ & $\begin{array}{l}\text { - Short Physical Performance Battery } \\
\text { (SPPB) }\end{array}$ & 12 & $\begin{array}{l}\text { - The Lifestyle Interventions and } \\
\text { Independence for Elders (LIFE) } \\
\text { - Similar to the study of Pohar et al. } 2014 \text { (26) }\end{array}$ & USA 2009 & Rejeski et al. (27) \\
\hline
\end{tabular}

\section{DISCUSSION}

This systematic review provides available evidence about the impact of cognitive, physical, and multicomponent interventions on the elderly's independence in IADLs and BADLs.
Cognitive programs sought to prevent the reduction of executive functions and other aspects of working memory that is damaged during the aging process (37). According to the results, cognitive interventions had two outcomes: improving independence in IADLs and BADLs. As a cognitive program, 
SMP strengthened the elderly's independence in IADLs by improving internal locus of control, participation, problemsolving, and self-determination skills (28). It is justified in light of the self-efficacy theory that the internal control mechanism can gradually control the individual's behaviors and allows the person to adapt to the social and physical environment (38). Rebok et al. also showed that active cognitive training effectively improved IADLs in the elderly for 10 years (12). The "Insight program" enhanced BADLs in the elderly by using computer games stimulated parts of the brain that controls movements (29). This program therefore focused on executive functions that include selective attention and working memory (39). Selective attention can solve the problems of essential cognitive ability and improve BADLs (40). Researchers in a study stated that video game training could significantly enhance the elderly's cognitive and physical performance, independence, and right to choose (41). The weakness of these two studies was the lack of evaluation of IADLs and BADLs simultaneously.

The results showed that the outcome of physical intervention was the improvement of independence in BADLs. The "threestep workout for life program" (24) and "water exercise training program" (25) focused on physical activity and improving familiar and simple activities for promoting the elderly's independence in BADLs. Physical exercise is an efficient and costeffective way to prevent the loss of the elderly's functional ability (42). Physical activity's positive effects include independence in self-care activities, higher self-esteem, better life quality, higher life expectancy, and lower mortality (43). Some studies state that exercise can delay elderly dependence and improve physical performances, such as sitting and standing, maintaining balance, and movement $(44,45)$. Chou et al. support this finding that exercise training interventions are beneficial to boost walking speed and improve balance and performance in the elderly's ADLs (10).

Multicomponent interventions had a variety of consequences. LIFE intervention improved BADLs $(26,27)$ and focused on psychological empowerment, concepts of Bandura's social cognitive theory (46), and a group-mediated approach (47). This method leads to the internalization of the locus of control (48). The results of Blankevoort et al.'s study support this finding and indicate multicomponent interventions can improve the elderly's physical performance and BADLs (49). Bandura's cognitive theory justifies how enhancing self-efficacy beliefs and outcome expectations in the elderly increases their selfconfidence and sense of control over life and make them more independent (50). According to these results, in two programs of the "continuum of care for frail older people" (23) and the "EPRZ" (51), researchers have been able to purposefully improve the independence of the elderly in both IADLs and BADLs. It should be noted that tailoring interventions can be designed as cognitive, physical, or combined interventions based on independence in IADLs or BADLs. Also, the emphasis on creating an age-friendly environment is very valuable in EPRZ because it is made in accordance with the restrictions of the elderly and preserves their independence. In a study consistent with this finding, researchers stated that combined interventions should be tailored based on the elderly's needs and preferences to build a safe and independent life for them (18).

\section{A Proposed Logic Model for Designing Intervention}

Given that independence has different dimensions and is known as a multifactorial phenomenon, it requires tailored multifaceted interventions $(52,53)$. It seems that the design and evaluation of multicomponent interventions using standard protocols in different elderly populations should be considered in future studies. On the other hand, individual socioeconomic differences among the elderly indicate that tailoring interventions are necessary. Therefore, inspired by the logical models in health promotion program planning, we developed a conceptual framework for designing multicomponent interventions to promote the elderly's independence in activities of daily living. The main components of our proposed logic model are plotted in Figure 4 and described below.

In the input, situational analysis performs. In our logic model, situation analysis refers to analyzing a collection of the elderly's individual strengths and weaknesses and opportunities and threats of physical and social environments (SWOT analysis).

The process section shows the methods and activities designed to implement the interventions and provide services to the target audience (54). According to the situational analysis, this phase uses problem-based interventions, including cognitive, physical, and multicomponent interventions. Creating an agefriendly environment is also considered to maintain the elderly's independence in our proposed model. According to the WHO, health is affected by how people live, and the physical and social environment can affect people's health-oriented behavior (55). Therefore, it is necessary to design cities and elderly's homes under age-friendly environments. The third component of the process is the need for economic, psychological, and social support to sustain the elderly's independence, which can be achieved through family, friends, NGOs, and the government.

The output demonstrates the achievements of a program in the target audience (56), and it was specified in our logic model as having improved the elderly's independence in ADLs.

\section{CONCLUSION}

This systematic review provides a useful overview of effective interventions to improve the elderly's independence in ADLs. The development of a conceptual framework is the novelty of this study, which provides a better insight to design interventions for the elderly's independence. We recommend the use of standard protocols for the design, implementation, and evaluation of interventions because it can help to better compare interventions in systematic review and meta-analysis studies. Our proposed logic model can, therefore, be tested as a guiding framework in the design of interventions. Another systematic review should also be performed-one that focuses on a specific type of intervention, such as cognitive interventions.

\section{Limitation}

In its binding to English-language publications, the studies' geographical scope has been limited. Also, the studies done in 


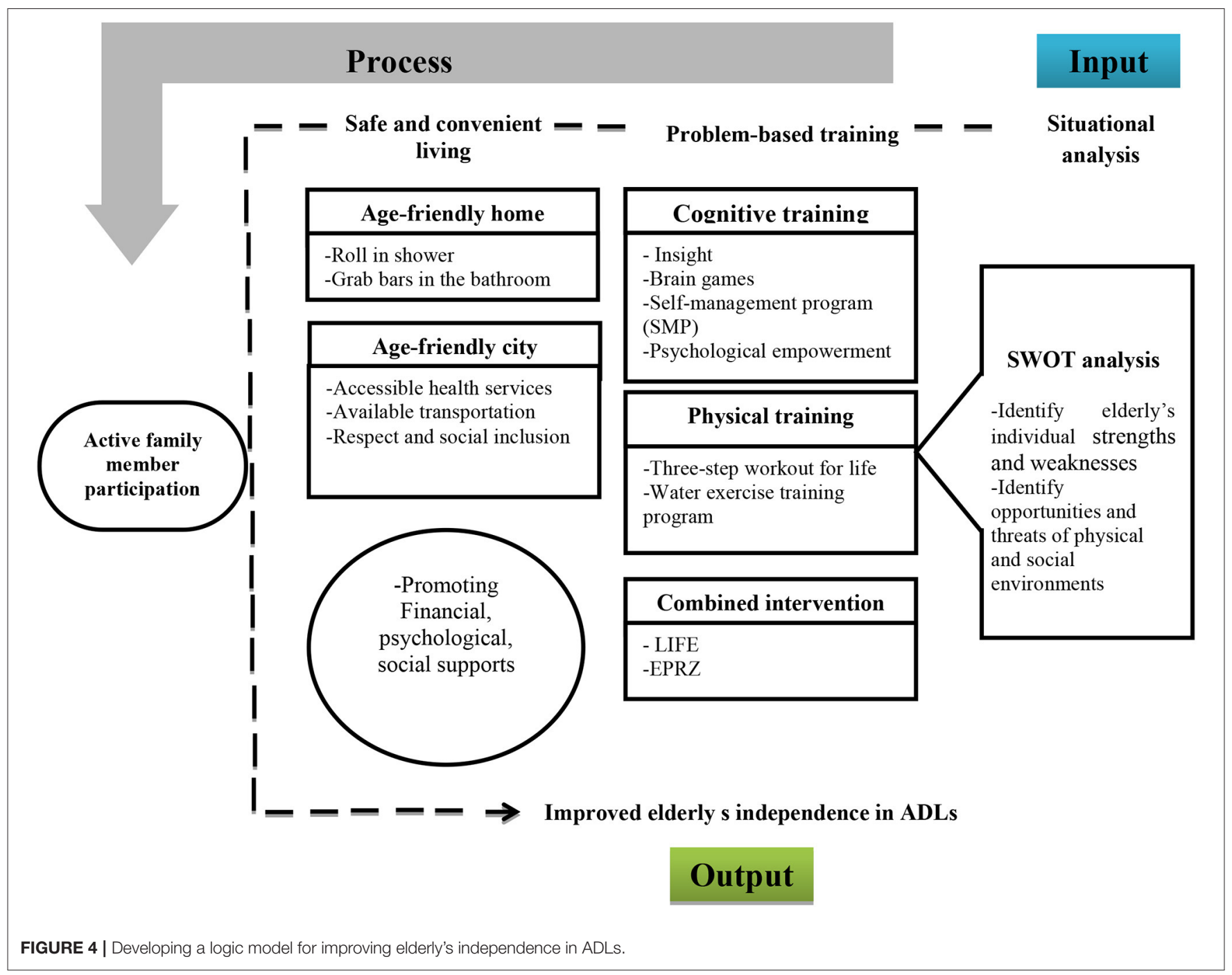

Persian but not indexed in English databases were not included in the strategy search. In the present study, the meta-analysis was not performed due to shortcomings in quantitative indices and different measuring tools.

\section{DATA AVAILABILITY STATEMENT}

All datasets generated for this study are included in the article/Supplementary Material.

\section{REFERENCES}

1. Dworkin G. The Theory and Practice of Autonomy. Cambridge: Cambridge University Press (1988). doi: 10.1017/CBO9780511625206

2. Jacelon CS. Older adults and autonomy in acute care: increasing patients' independence and control during hospitalization. J Gerontol Nurs. (2004) 30:29-36. doi: 10.3928/0098-9134-20041101-10

3. Bach M, Kerzner L. A New Paradigm for Protecting Autonomy and the Right to Legal Capacity. Toronto, ON: Law Commission of Ontario (2014).

\section{AUTHOR CONTRIBUTIONS}

MK and MM-J collaborated equally on all parts of this manuscript.

\section{SUPPLEMENTARY MATERIAL}

The Supplementary Material for this article can be found online at: https://www.frontiersin.org/articles/10.3389/fpubh. 2020.516151/full\#supplementary-material

4. Karakaya MG, Bilgin SÇ, Ekici G, Köse N, Otman AS. Functional mobility, depressive symptoms, level of independence, and quality of life of the elderly living at home and in the nursing home. $J$ Am Med Dir Assoc. (2009) 10:662-6. doi: 10.1016/j.jamda.2009. 06.002

5. Lopez-Hartmann M, Wens J, Verhoeven V, Remmen RJ. The effect of caregiver support interventions for informal caregivers of communitydwelling frail elderly: a systematic review. Int J Integr Care. (2012) 12:e133. doi: $10.5334 /$ ijic. 845 
6. Jekel K, Damian M, Wattmo C, Hausner L, Bullock R, Connelly PJ, et al. Mild cognitive impairment and deficits in instrumental activities of daily living: a systematic review. Alzheimers Res Ther. (2015) 7:17. doi: 10.1186/s13195-015-0099-0

7. Lawton MP, Brody EM. Assessment of older people: self-maintaining and instrumental activities of daily living. Gerontologist. (1969) 9(3_Part_1):17986. doi: 10.1093/geront/9.3_Part_1.179

8. Oleson M, Heading C, McGlynn K, Bistodeau JA. Quality of life in long-stay institutions in England: nurse and resident perceptions. J Adv Nurs. (1994) 20:23-32. doi: 10.1046/j.1365-2648.1994.20010023.x

9. Lee TW, Ko IS, Lee KJ. Health promotion behaviors and quality of life among community-dwelling elderly in Korea: a cross-sectional survey. Int J Nurs Stud. (2006) 43:293-300. doi: 10.1016/j.ijnurstu.2005.06.009

10. Chou C-H, Hwang C-L, Wu Y-T. Effect of exercise on physical function, daily living activities, and quality of life in the frail older adults: a meta-analysis. Arch Phys Med Rehabil. (2012) 93:237-44. doi: 10.1016/j.apmr.2011.08.042

11. Liu C-J, Shiroy DM, Jones LY, Clark DO. Systematic review of functional training on muscle strength, physical functioning, and activities of daily living in older adults. Eur Rev Aging Phys Act. (2014) 11:95106. doi: 10.1007/s11556-014-0144-1

12. Rebok GW, Ball K, Guey LT, Jones RN, Kim HY, King JW, et al. Ten-year effects of the advanced cognitive training for independent and vital elderly cognitive training trial on cognition and everyday functioning in older adults. J Am Geriatr Soc. (2014) 62:16-24. doi: 10.1111/jgs.12607

13. Willis SL, Tennstedt SL, Marsiske M, Ball K, Elias J, Koepke KM, et al. Longterm effects of cognitive training on everyday functional outcomes in older adults. JAMA. (2006) 296:2805-14. doi: 10.1001/jama.296.23.2805

14. Mortazavi H, Tabatabaeichehr M, Taherpour M, Masoumi M. Relationship between home safety and prevalence of falls and fear of falling among elderly people: a cross-sectional study. Materia Socio Med. (2018) 30:103. doi: 10.5455/msm.2018.30.103-107

15. Bullo V, Bergamin M, Gobbo S, Sieverdes J, Zaccaria M, Neunhaeuserer D, et al. The effects of Pilates exercise training on physical fitness and wellbeing in the elderly: a systematic review for future exercise prescription. Prev Med. (2015) 75:1-11. doi: 10.1016/j.ypmed.2015.03.002

16. Giné-Garriga M, Roqué-Fíguls $M$, Coll-Planas L, Sitja-Rabert M, Salvà A. Physical exercise interventions for improving performance-based measures of physical function in community-dwelling, frail older adults: a systematic review and meta-analysis. Arch Phys Med Rehabil. (2014) 95:753-69. e3. doi: 10.1016/j.apmr.2013.11.007

17. Vagetti GC, Barbosa Filho VC, Moreira NB, Oliveira VD, Mazzardo O, Campos WD. Association between physical activity and quality of life in the elderly: a systematic review, 2000-2012. Rev Bras Psiquiatr. (2014) 36:7688. doi: 10.1590/1516-4446-2012-0895

18. Beswick AD, Rees K, Dieppe P, Ayis S, Gooberman-Hill R, Horwood J, et al. Complex interventions to improve physical function and maintain independent living in elderly people: a systematic review and meta-analysis. Lancet. (2008) 371:725-35. doi: 10.1016/S0140-6736(08)60342-6

19. Moher D, Liberati A, Tetzlaff J, Altman DG. Preferred reporting items for systematic reviews and meta-analyses: the PRISMA statement. Ann Intern Med. (2009) 151:264-9. doi: 10.7326/0003-4819-151-4-200908180-0 0135

20. Institute JB. User Manual: Version 5.0 System for the Unified Management, Assessment and Review of Information (2012). Retrieved from: https://nursing. lsuhsc.edu/JBI/docs/ReviewersManuals/Umbrella\%20Reviews.pdf

21. Tacconelli E. Systematic reviews: CRD's guidance for undertaking reviews in health care. Lancet Infect Dis. (2010) 10:226. doi: 10.1016/S1473-3099(10)70065-7

22. Dahlin-Ivanoff S, Eklund K, Wilhelmson K, Behm L, Häggblom-Kronlöf G, Zidén L, et al. For whom is a health-promoting intervention effective? Predictive factors for performing activities of daily living independently. BMC Geriatr. (2016) 16:1-9. doi: 10.1186/s12877-016-0345-8

23. Eklund K, Wilhelmson K, Gustafsson H, Landahl S, Dahlin-Ivanoff S. Oneyear outcome of frailty indicators and activities of daily living following the randomised controlled trial; "Continuum of care for frail older people". BMC Geriatr. (2013) 13:1-10. doi: 10.1186/1471-2318-13-76

24. Liu C-J, Jones LY, Formyduval AR, Clark DO. Task-oriented exercise to reduce activities of daily living disability in vulnerable older adults: a feasibility study of the 3-step workout for life. J Aging Phys Activity. (2016) 24:384-92. doi: 10.1123/japa.2015-0070

25. Martínez PYO, López JAH, Hernández AP, Dantas EHM. Effect of periodized water exercise training program on functional autonomy in elderly women. Nutr Hospital. (2015) 31:351-6. doi: 10.3305/nh.2015.31.1.7857

26. Pahor M, Guralnik JM, Ambrosius WT, Blair S, Bonds DE, Church TS, et al. Effect of structured physical activity on prevention of major mobility disability in older adults: the LIFE study randomized clinical trial. JAMA. (2014) 311:2387-96. doi: 10.1001/jama.2014.5616

27. Rejeski WJ, Marsh AP, Chmelo E, Prescott AJ, Dobrosielski M, Walkup $\mathrm{MP}$, et al. The lifestyle interventions and independence for elders pilot (LIFE-P):2-year follow-up. J Gerontol A Biomed Sci Med Sci. (2009) 64:462. doi: $10.1093 /$ gerona/gln041

28. Roets-Merken LM, Zuidema SU, Vernooij-Dassen MJ, Teerenstra S, Hermsen PG, Kempen GI, et al. Effectiveness of a nurse-supported self-management programme for dual sensory impaired older adults in long-term care: a cluster randomised controlled trial. BMJ Open. (2018) 8:e016674. doi: 10.1136/bmjopen-2017-016674

29. Smith-Ray RL, Makowski-Woidan B, Hughes SL. A randomized trial to measure the impact of a community-based cognitive training intervention on balance and gait in cognitively intact black older adults. Health Educ Behav. (2014). 41:62S-9. doi: 10.1177/1090198114537068

30. Vernooij-Dassen MJ, Osse BH, Schadé E, Grol RP. Patient autonomy problems in palliative care: systematic development and evaluation of a questionnaire. J Pain Sympt Manage. (2005) 30:264-70. doi: 10.1016/j.jpainsymman.2005.03.010

31. Baum C, Edwards D. Activity Card Sort. 2nd ed. Bethesda, MD: AOTA Press (2008).

32. Lorig KR, Holman HR. Self-management education: history, definition, outcomes, and mechanisms. Ann behave Med. (2003) 26:1-7. doi: 10.1207/S15324796ABM2601_01

33. Jakobsson U. The ADL-staircase: further validation. Int J Rehabil Res. (2008) 31:85-8. doi: 10.1097/MRR.0b013e3282f45166

34. Pernambuco CS, Borba-Pinheiro CJ, de Souza Vale RG, Di Masi F, Monteiro PKP, Dantas EH. Functional autonomy, bone mineral density (BMD) and serum osteocalcin levels in older female participants of an aquatic exercise program (AAG). Arch Gerontol Geriatr. (2013) 56:466-71. doi: 10.1016/j.archger.2012.12.012

35. Blair SN, Mark E, Roger F, Gill TM, Guralnik JM, Hadley EC, et al. Effects of a physical activity intervention on measures of physical performance: results of the lifestyle interventions and independence for Elders Pilot (LIFE-P) study. J Gerontol A Biol Sci Med Sci. (2006) 61:1157-65. doi: 10.1093/gerona/61.11.1157

36. Marsh AP, Lovato LC, Glynn NW, Kennedy K, Castro C, Domanchuk K, et al. Lifestyle interventions and independence for elders study: recruitment and baseline characteristics. J Gerontol A Biomed Sci Med Sci. (2013) 68:1549-58. doi: 10.1093 /gerona/glt064

37. Thompson TW, Waskom ML, Garel K-LA, Cardenas-Iniguez C, Reynolds GO, Winter R, et al. Failure of working memory training to enhance cognition or intelligence. PLOS ONE. (2013) 8:e63614. doi: 10.1371/journal.pone.0063614

38. Schmeichel BJ, Zell A. Trait self?control predicts performance on behavioral tests of self-control. J Personal. (2007) 75:74356. doi: 10.1111/j.14676494.2007.00455.x

39. Ballesteros S, Mayas J, Prieto A, Ruiz-Marquez E, Toril P, Reales JM, Fian J. Effects of video game training on measures of selective attention and working memory in older adults: results from a randomized controlled trial. Front Aging Neurosci. (2017) 9:354. doi: 10.3389/fnagi.2017.00354

40. Owsley C, Sloane M, McGwin Jr G, Ball KJG. Timed instrumental activities of daily living tasks: relationship to cognitive function and everyday performance assessments in older adults. (2002) 48:254-65. doi: 10.1159/000058360

41. Maillot P, Perrot A, Hartley A. Effects of interactive physical-activity videogame training on physical and cognitive function in older adults. Psychol Aging. (2012) 27:589. doi: 10.1037/a0026268

42. Cadore EL, Rodríguez-Mañas L, Sinclair A, Izquierdo M. Effects of different exercise interventions on risk of falls, gait ability, and balance in physically frail older adults: a systematic review. Rejuvenat Res. (2013) 16:105-14. doi: $10.1089 /$ rej.2012.1397 
43. Cvecka J, Tirpakova V, Sedliak M, Kern H, Mayr W, Hamar Da. Physical activity in elderly. Eur J Transl Myol. (2015) 25:249. doi: 10.4081/ejtm.2015.5280

44. Liu Cj, Latham NK. Progressive resistance strength training for improving physical function in older adults. Cochrane Database Syst Rev. (2009) 2009:CD002759. doi: 10.1002/14651858.CD002759.pub2

45. Peri K, Kerse N, Robinson E, Parsons M, Parsons J, Latham N. Does functionally based activity make a difference to health status and mobility? A randomised controlled trial in residential care facilities (The Promoting Independent Living Study; PILS). Age Ageing. (2007) 37:57-63. doi: 10.1093/ageing/afm 135

46. Bandura A. 6 Social foundations of thought and action. Health Psychol Reader. (2002) 2002:94.

47. Rejeski WJ, Brawley LR, Ambrosius WT, Brubaker PH, Focht BC, Foy CG, et al. Older adults with chronic disease: benefits of group-mediated counseling in the promotion of physically active lifestyles. Health Psychol. (2003) 22:414. doi: 10.1037/0278-6133.22.4.414

48. Weiner B, Heckhausen H, Meyer W-U. Causal ascriptions and achievement behavior: a conceptual analysis of effort and reanalysis of locus of control. J Personal Soc Psychol. (1972) 21:239. doi: 10.1037/h00 32307

49. Blankevoort CG, Van Heuvelen MJ, Boersma F, Luning H, De Jong J, Scherder EJ. Review of effects of physical activity on strength, balance, mobility and ADL performance in elderly subjects with dementia. Dement Geriatr Cognit Disord. (2010) 30:392-402. doi: 10.1159/0003 21357

50. Wahba H, Chang Y-FJI. Factors associated with glycemic control in patients with type 2 diabetes mellitus in rural areas of the United States. Insulin. (2007). 2:134-41. doi: 10.1016/S1557-0843(07)8 0042-X
51. Dahlin-Ivanoff S, Gosman G, Edberg A-K, Wilhelmson K, Eklund K, Duner $\mathrm{A}$, et al. Elderly persons in the risk zone. Design of a multidimensional, health-promoting, randomised three-armed controlled trial for "prefrail" people of $80+$ years living at home. BMC Geriatr. (2010) 10:27. doi: 10.1186/1471-2318-10-27

52. Hillcoat-Nallétamby S. The meaning of "independence" for older people in different residential settings. J Gerontol B Psychol Sci Soc Sci. (2014) 69:419-30. doi: 10.1093/geronb/gbu008

53. Al-Aama T. Falls in the elderly: spectrum and prevention. Can Fam Phys. (2011) 57:771-6.

54. Turnock B. Essentials of Public Health. Chicago, IL: Jones \& Bartlett Publishers (2011).

55. Health CoSDo. Closing the Gap in a Generation: Health Equity Through Action on the Social Determinants of Health: Final Report of the Commission on Social Determinants of Health. Geneva: World Health Organization (2008).

56. Keane C. Modeling Behavior in Complex Public Health Systems: Simulation and Games for Action and Evaluation. New York, NY: Springer Publishing Company (2013).

Conflict of Interest: The authors declare that the research was conducted in the absence of any commercial or financial relationships that could be construed as a potential conflict of interest.

Copyright (c) 2021 Motamed-Jahromi and Kaveh. This is an open-access article distributed under the terms of the Creative Commons Attribution License (CC BY). The use, distribution or reproduction in other forums is permitted, provided the original author(s) and the copyright owner(s) are credited and that the original publication in this journal is cited, in accordance with accepted academic practice. No use, distribution or reproduction is permitted which does not comply with these terms. 